Jurnal Teknik Komputer AMIK BSI

Volume 7, No.2, Juli 2021

P-ISSN 2442-2436, E-ISSN: 2550-0120

Akreditasi Ristekdikti, No: 36/E/KPT/2019 (Sinta 4)

DOI: $10.31294 /$ jtk.v4i2

\title{
Perancangan Ruang Data Center Bank XYZ Menggunakan Standar ANSI/BICSI 002 dan Metode PPDIOO
}

\author{
Andi Rosano ${ }^{1}$, Djadjat Sudaradjat ${ }^{2}$ \\ ${ }^{1,2}$ Universitas Bina Sarana Informatika \\ 1e-mail: andi.aox@bsi.ac.id \\ 2e-mail: djadjat.dsj@bsi.ac.id
}

\begin{tabular}{ccc}
\hline Diterima & Direvisi & Disetujui \\
$24-05-2021$ & $14-06-2021$ & $24-06-2021$ \\
\hline
\end{tabular}

\begin{abstract}
Abstrak - Semakin pesatnya perkembangan teknologi informasi saat ini telah menyebabkan semua proses yang berkaitan dengan TI menjadi terpusat serta mudah dikelola, hal ini dimungkinkan karena meluasnya penggunaan jaringan internet, intranet ataupun keduanya. Data center adalah satu contoh fasilitas yang memanfaatkan teknologi informasi yang beroperasi secara terpusat, sehingga pengelolaan menjadi mudah serta dapat mendukung proses bisnis di bidangnya. Bank XYZ telah memiliki data center dalam upaya mendukung proses pelayanan nasabah agar menjadi terpusat dan lebih praktis karena telah tersedianya koneksi internet. Namun keberadaan data center tersebut belum sesuai standar internasional yang ditetapkan oleh ANSI/BICSI 002. Perlu dibuat suatu rancangan perubahan sehingga data center yang ada memiliki standar baku, terutama untuk perencanaan ruang (space planning) pada data center Bank XYZ. Rancangan data center ini harus memenuhi aspek dan ruang lingkup diantaranya adalah sistem tenaga listrik (power systems), pembangkit tenaga listrik (generator), keamanan (security), dan ruang support data center (supporting spaces). Penelitian yang dilakukan ini adalah melakukan analisa guna memberikan usulan rancangan data center dan sistem bangunannya, berdasarkan standar ANSI/BICSI 002. Hasil akhir penelitian ini adalah usulan rancangan ruangan data center yang dapat diimplementasikan untuk Bank XYZ.
\end{abstract}

Kata Kunci: data center, ANSI/BICSI 002, space planning, power systems, security, supporting spaces

\begin{abstract}
The rapid development of information technology today has caused all IT-related processes to become centralized and easy to manage, this is possible due to the widespread use of internet, intranet or both networks. The data center is an example of a facility that utilizes information technology that operates centrally, so that management is easy and can support business processes in their respective fields. Bank XYZ already has a data center in an effort to support the customer service process so that it becomes centralized and more practical due to the availability of an internet connection. However, the existence of the data center is not in accordance with the international standards set by ANSI / BICSI 002. It is necessary to make a design change so that the existing data center has standard standards, especially for space planning at the XYZ Bank data center. The design of this data center must meet the aspects and scope of which include power systems, power generators, security, and data center support spaces (supporting spaces). The research conducted is to analyze in order to provide a data center design proposal and its building system, based on ANSI / BICSI 002 standards. The final result of this study is a proposed data center room design that can be implemented for XYZ Bank.
\end{abstract}

Keywords: data center, ANSI/BICSI 002, space planning, power systems, security, supporting space

\section{PENDAHULUAN}

Di masa sekarang ini, perkembangan Teknologi Informasi (TI) amatlah cepat, terbukti dengan makin canggihnya dunia TI yang berkembang setiap saat dari waktu ke waktu. Semakin canggihnya TI masa kini telah memberikan kemudahan pada kita untuk berkomunikasi, antara lain bertukar sumber informasi dalam bentuk data, suara, video, dan sebagainya. Perkembangan TI juga menyebabkan munculnya bermacam aktivitas sosial dan ekonomi yang berbasis teknologi, seperti e-commerce, e- education, dan e-government (Wardiana, 2012) dimana tiap aktivitas masing-masing saling membutuhkan pertukaran data secara elektronik.

Data sebenarnya adalah salah satu bentuk komunikasi dalam pertukaran informasi yang terjadi saat ini, utamanya data digital. Data adalah sesuatu yang sangat berharga dan merupakan aset bagi pemiliknya. Contohnya data nasabah pada bank, data pegawai pada perusahaan atau instansi pemerintahan, dan sebagainya yang tentu sangat berharga. Oleh sebab itu diperlukan sebuah tempat 
penyimpanan data terpusat dan aman agar data yang merupakan aset ini dapat dikelola sebaik-baiknya dan dapat dengan mudah diakses oleh pihak yang berkepentingan. Hal inilah yang menjadi masalah penting yang harus diselesaikan. Pada saat ini para ahli TI telah berhasil menemukan suatu teknologi penyimpanan data secara terpusat, dan aksesnya pun dilengkapi bermacam fitur pengamanan. Inilah teknologi informasi yang disebut data center.

Data center sebenarnya adalah server atau ruang komputer tempat berkumpulnya beberapa server perusahaan (Bullock, 2009). Data center adalah tempat penyimpan data dan juga berfokus pada pembawa layanan informasi jaringan dan Internet (Ye, H.; Song, Z.; Sun, 2014). Dengan demikian data center saat ini telah menjadi cabang TI yang paling banyak digunakan lembaga atau perusahaan, seperti instansi pemerintahan, bank, institusi pendidikan, dan perusahaan besar lain, dengan tujuan untuk peningkatan layanan dan daya saing dengan lembaga atau perusahaan lain dalam melayani stakeholdersnya. Ujungnya adalah peningkatan efektivitas pada proses bisnis masingmasing lembaga atau perusahaan tersebut.

Faktor penempatan hardware pada data center harus mempertimbangkan posisi dan ukuran yang cocok sehingga setiap komponen hardware dapat berfungsi optimal. Dengan semakin banyaknya utilisasi data center, tentunya dibutuhkan suatu disain ruangan yang tepat agar data center beroperasi dengan optimal. Teknologi ruangan dan hardware yang dibutuhkan untuk data center berkembang semakin canggih dari tahun ke tahun. Oleh karena itu sangatlah penting dalam hal ini space planning, agar data center yang dibangun beroperasi optimal dan sesuai standar yang berlaku internasional.

Space planning merupakan kegiatan perencanaan data center, entrance room, loading dock, storage room, build room, dan backup room (Yulianti, D.E.; Nanda, 2008). Perancangan tata kelola dan penempatan ruang yang tepat untuk data center. Perancangan ini juga harus menyediakan ruangan mana yang dapat dikembangkan mengikuti perubahan teknologi dan pertumbuhan kebutuhan. Dengan kata lain data center harus mempunyai banyak white space, yaitu ruang kosong yang dapat menampung pertambahan rak di masa mendatang. Ruang lingkungan di sekitar data center harus dipertimbangkan bila di masa depan perlu melakukan penggabungan ruangan. Dikatakan oleh Diah Eka Yulianti dan Nanda bahwa untuk mendapat kinerja yang optimal data center perlu dilengkapi dengan beberapa ruang pendukung di antaranya adalah ruang server, ruang panel listrik, operation command.
Bank XYZ yang sudah berkembang dengan pesat dan memiliki jumlah nasabah sangat besar dengan kantor cabang yang ada di seluruh Indonesia, tentunya telah memiliki data center. Namun demikian dengan perkembangan bisnis dan jaringan bank dirasakan perlu membangun kembali suatu data center berstandar internasional, dengan pengelolaan yang lebih profesional. Berdasarkan banyaknya jumlah nasabah dan cabang yang beroperasi di Bank XYZ, maka manajemen bank merasa sangat membutuhkan sebuah data center yang dapat bekerja secara optimal dengan hardware yang memiliki spesifikasi yang sesuai untuk pengoperasian sistem serta beberapa kebutuhan lain yang berstandar internasional.

ANSI/BICSI 002 adalah standard design dan best practice untuk implementasi data center yang tujuannya adalah standarisasi persyaratan instalasi data center dan merupakan panduan atau pedoman implementasi desain suatu data center. Selain hal tersebut, metodologi penelitian yang dipakai juga sangat penting, karena dengan adanya metodologi maka setiap proses yang dilakukan dapat berjalan dengan baik dan sesuai aturan, metode PPDIOO Network Life-Cycle Approach yang sudah disahkan oleh Cisco Systems adalah suatu pendekatan yang memiliki 6 fase dalam mendesain suatu jaringan, dan dapat diatur dengan kebutuhan pelanggan, tujuan organisasi, batasan organisasi, tujuan teknis, dan batasan teknis yang harus diidentifikasi (Systems, 2007).

\section{METODOLOGI PENELITIAN}

\subsection{Pengertian Data Center}

Data center mengandung sumber daya komputasi terpenting dimana seluruh perangkat terletak dalam lingkungan yang terkontrol dibawah kendali terpusat, dengan menggunakan teknologi informasi yang pendukung keberlangsungan bisnis serta dapat melakukan operasi-operasi bisnis bila dibutuhkan. Data center bersifat kritis, dan teknologi yang dipakai pada sebuah data center akan terus menerus berevolusi seiring bertambahnya ketergantungan organisasi terhadapnya. Sehingga faktor keamanan dan efektivitas adalah suatu kebutuhan yang mutlak untuk sebuah data center dan harus dipenuhi. Apabila desain jaringan data center tidak dapat memenuhi tingkat layanan yang diminta atau Service Level Agreement, dianggap tidak memenuhi kebutuhan (Arregoces, M; Portolani, 2004).

Pengertian data center adalah peralatan elektronik utama yang digunakan untuk melakukan pengolahan data, tempat penyimpanan data, dan menjadi tempat peletakan alat-alat komunikasi. Secara kolektif data center adalah tempat dimana semua perangkat 
telekomunikasi terkumpul, tempat penyimpanan data, serta merupakan sumber informasi digital yang dikirimkan dan diterima. Data center mempunyai daya khusus dan perangkat cadangan yang berfungsi menjaga agar selalu tersedia layanannya. Daya yang dimiliki berkualitas tinggi dan dilengkapi dengan perangkat pendingin untuk menjaga stabilitas suhu dalam ruangan (Geng, 2014).

Definisi lain, data center juga merupakan fasilitas yang digunakan untuk penempatan beberapa kumpulan server dalam sistem komputer dan sistem penyimpanan data yang dibuat sedemikian rupa dengan pengaturan catu daya, pengaturan udara, pencegahan bahaya kebakaran, dan dilengkapi pula dengan pengamanan fisik (Yulianti, D.E.; Nanda, 2008).

Data center juga dikenal sebagai kumpulan server atau ruang komputer, dimana data center merupakan ruangan sebagian besar server dan penyimpanan data perusahaan terletak, beroperasi, dan diatur. Terdapat empat komponen utama Data Center: (1) white space, (2) infrastruktur pendukung, (3) peralatan Teknologi Informasi, dan (4) Operation (Bullock, 2009).

\subsection{Standar ANSI/BICSI 002}

ANSI/BICSI 002 merupakan Standard Design dan Best Practice dalam implementasi Data Center. Tujuan ANSI/BICSI 002 adalah sebagai standar persyaratan instalasi data center dan merupakan panduan/pedoman implementasi desain data center. ANSI/BICSI 002 juga sering diimplementasikan bersama standar lainnya seperti ANSI/TIA-942, AS/NZS 2834, CENELEC EN 50173-5, ISO/IEC 24764 (Tampa, 2011).

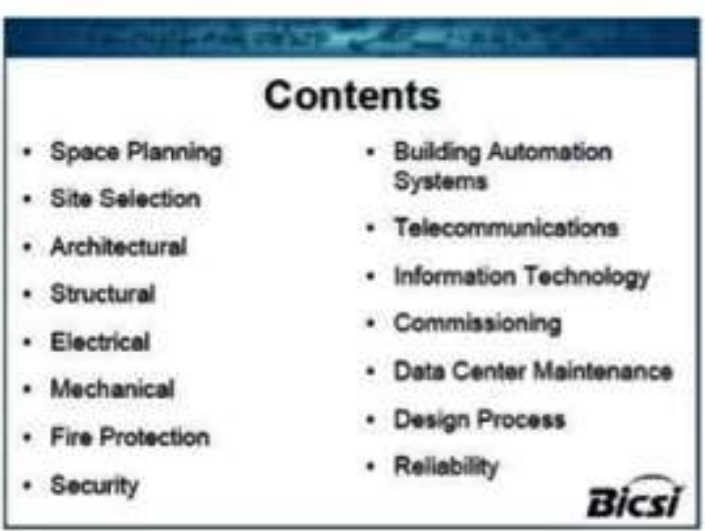

Gambar 1 Konten ANSI/BICSI 002

\subsection{Perencanaan Ruang}

Perencanaan ruang untuk data center yang ideal dimulai dengan memastikan bahwa ruangan tersebut dapat dengan mudah dilakukan perubahan atau fleksibel mengikuti pertumbuhan dan kebutuhan.
Untuk itu data center harus dirancang memiliki banyak "white space" atau ruang kosong yang dapat menampung rak-rak atau mesin baru kedepannya. Selain itu rancangan ruang data center harus memperhitungkan perkembangan yang mungkin akan terjadi di masa depan. Sehingga mudah untuk dilakukan penggabungan bilamana diperlukan. Untuk mengoptimalkan kinerja data center perlu dilengkapi beberapa ruangan pendukung di antaranya (Yulianti, D.E.; Nanda, 2008) :

1. Ruang Server, ruangan dimana semua perangkat jaringan dan komputer yang terkait saling bekerja dan mengolah, menyediakan, menyimpan, serta menyalurkan data.

2. Ruang Kelistrikan, dimana ruangan yang berkaitan dengan kelistrikan untuk memenuhi kebutuhan perangkat data center dipisahkan dari ruang server guna untuk menghidari interferensi elektromagnetik.

3. Operation Command Center, ruangan ini digunakan untuk pegawai yang melakukan pemantauan atau monitoring aktivitas yang ada di dalam data center.

4 Fntranco Ronm ruanoan ini merunakan temnat
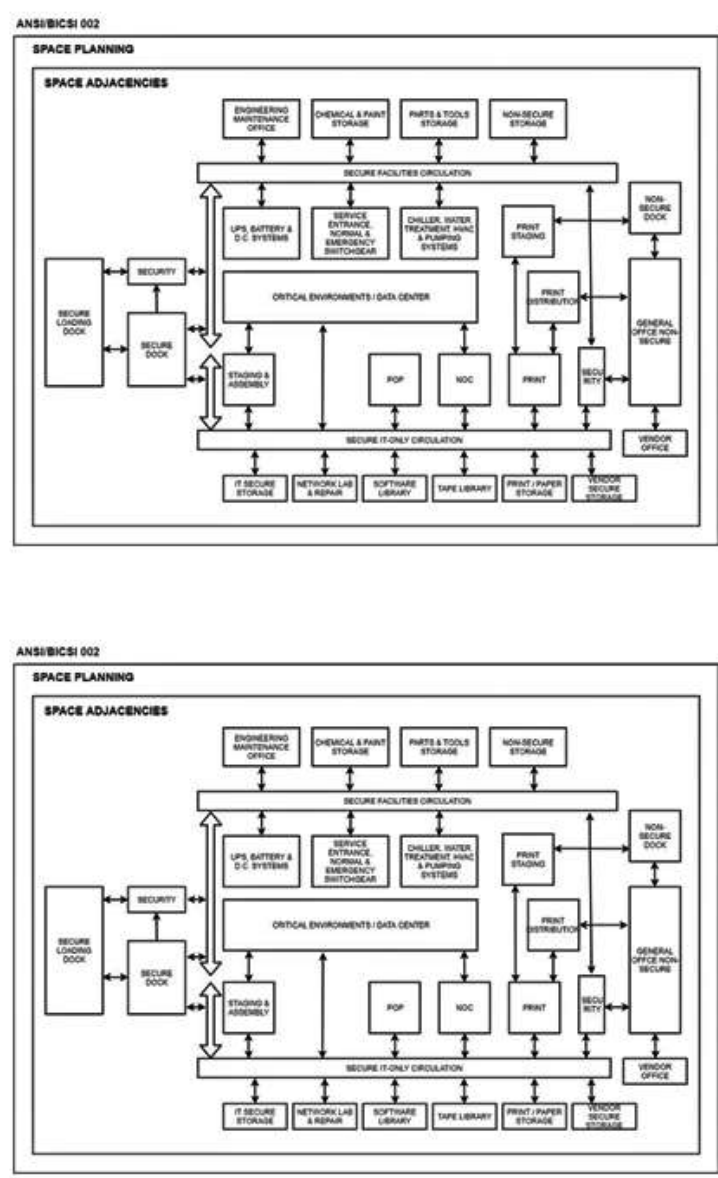

Gambar 2 Relationship of Space Adjacencies

\subsection{Metodologi Penelitian PPDIOO}




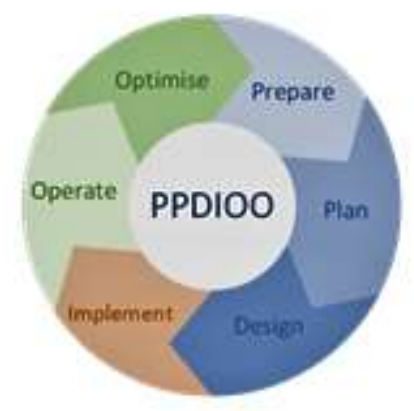

Gambar 3 PPDIOO Life Cycle Approach

Penelitian ini menerapkan metode PPDIOO hanya sampai tahap ketiga yaitu prepare phase (tahap persiapan), plan phase (tahap perencanaan, dan design phase (tahap disain). Berikut penjelasan 3 tahap yang digunakan pada penelitian ini (Direction, 2017), yaitu :

1. Tahap Persiapan. Pada tahap ini dilakukan penetapan kebutuhan bisnis dan visi yang sesuai dengan perencanaan strategi dan mengidentifikasi teknologi yang digunakan untuk mendukung rencana pertumbuhan, serta mengusulkan arsitektur dengan desain tingkat tinggi melalui sebuah pengujian. Pada tahap persiapan ini disusun rencana anggaran yang dibutuhkan dengan menyesuaikan kebutuhan dan kemampuan bisnis terhadap rancangan arsitektur yang diusulkan.

2. Tahap Perencanaan. Pada tahap ini dilakukan penentuan apakah kondisi saat ini mampu mendukung sistem yang diusulkan dengan melakukan analisis gap, memastikan ketersediaan sumberdaya dari perusahaan untuk mengelola teknologi dari desain hingga implementasi. Tahapan ini meneruskan dari tahap persiapan sebelumnya, dengan perencanaan yang baik maka akan mempermudah pengaturan pekerjaan, penanganan resiko yang mungkin muncul, permasalahan yang mungkin ditemui, serta menentukan sumber daya yang dibutuhkan

3. Tahap Disain. Pada tahap ini dibahas secara detail logika dari perancangan infrastruktur yang sesuai dengan mekanisme sistem, merancang mekanisme sistem yang akan bekerja sesuai dengan kebutuhan dan analisis. Dimana kebutuhan awal pada tahap perencanaan, antara lain adalah mengarahkan kegiatan desain khusus jaringan dan infrastruktur. Suatu desain yang dihasilkan harus selaras dengan tujuan bisnis dan spesifikasi teknis yang dapat meningkatkan kinerja jaringan, mendukung ketersediaan yang tinggi, kehandalan, keamanan, dan skalabilitas.

4. Model Konseptual. Model konseptual merupakan sebuah model yang memiliki keterkaitan dengan studi literatur serta membantu peneliti untuk melihat sebuah permasalah yang dihadapi dengan sudut pandang yang berbeda. Model konseptual juga membantu peneliti menentukan inti permasalah yang ada dan memberikan referensi untuk penyederhanaan permasalahan tersebut agar lebih mudah dipahami. Pada penelitian ini model konseptual menggambarkan kerangka desain data center pada Bank XYZ sesuai dengan standar.

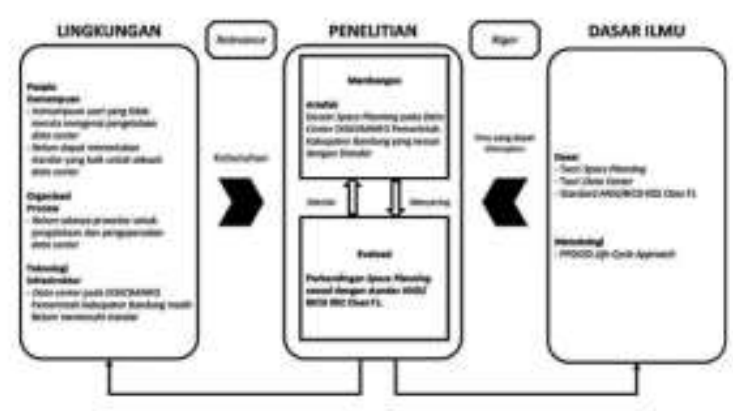

Gambar 4 Model Konseptual

Dari gambar di atas dapat terlihat model konseptual pada penelitian ini berawal dengan input berupa kondisi sistem keamanan data center saat ini pada Bank XYZ. Penelitian ini menggunakan metode PPDIOO Life Cycle Approach dengan batasan tahap yang dilakukan yaitu persiapan (prepare), perencanaan (plan) dan desain (design). Sedangkan evaluasi hasil penelitian ini akan dilakukan simulasi perancangan sistem keamanan data center. Untuk hasil akhir dari penelitian ini berupa rancangan desain usulan Rencana Ruang (space planning) Data Center sesuai standar ANSI/BICSI 002 pada Bank $\mathrm{XYZ}$.

\section{HASIL DAN PEMBAHASAN}

\subsection{Kondisi Data Center Saat Ini}

Dibawah ini adalah denah kondisi data center Bank XYZ saat ini : 


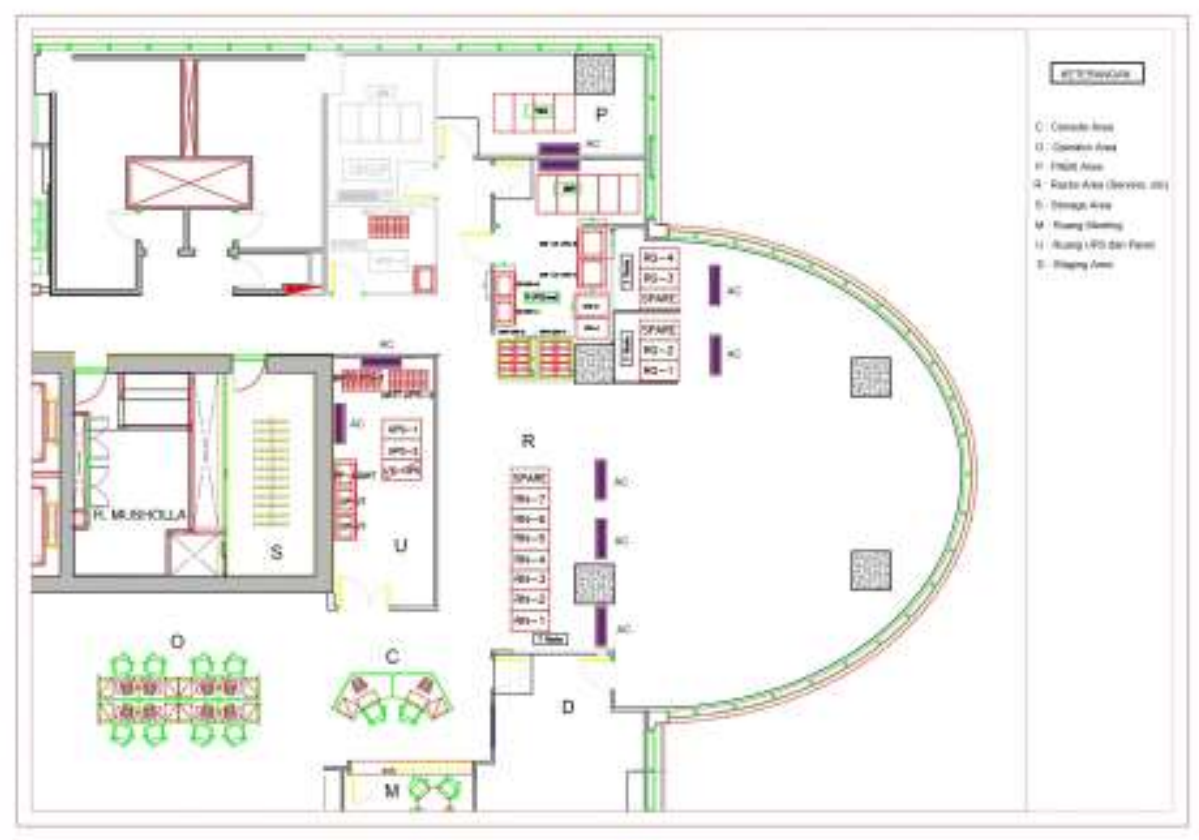

Gambar 5 Denah Data Center Bank XYZ Saat ini

Kondisi data center pada Bank XYZ telah memiliki 8 area, yaitu area console, area operator, area $P A B X$, area rak server, area storage, ruang pertemuan, area UPS dan panel, ruang locker staff/utilitas/gudang yang dapat dilihat pada gambar 5 area rak server terdiri dari 7 rak fungsional dan 1 rak cadangan yang masih kosong. Sistem pendingin pada data center Bank XYZ saat ini menggunakan 8 unit AC presisi yang masing-masing berkekuatan 15 Kva. Kapasitas daya listrik utama dari PLN adalah $100 \mathrm{Kva}$, dan telah ada 2 unit UPS dengan masing-masing berkapasitas $50 \mathrm{Kva}$, yang berfungsi untuk menggantikan sumber daya listrik utama sementara jika listrik utama mati. Generator untuk pembangkit listrik pengganti apabila pemadaman listrik melebihi kemampuan UPS, terletak di lantai basement pada gedung Bank XYZ.

Untuk jalur kabel data maupun listrik telah digunaan raised floor yang berukuran $60 \mathrm{~cm}$ x $60 \mathrm{~cm}$ dengan tinggi $30 \mathrm{~cm}$ dari lantai gedung. Semua kabel listrik dan data komunikasi diletakkan dibawah raised floor tersebut. Ruang penyimpanan backup data sudah tersedia namun dengan kapasitas terbatas. Ruang pertemuan untuk rapat tersedia namun hanya cukup menampung kurang dari 8 orang. Pada ruang UPS terdapat panel-panel utama dan switch pemindah otomatis listrik PLN ke UPS. Generator dinyalakan secara manual berdasarkan perhitungan kapasitas UPS. Pada dasarnya data center di Bank XYZ belum memiliki standar baku untuk pengembangan ke depan, sehingga dikhawatirkan kapasitas dan pengelolaan data center akan terbatas dalam waktu dekat.
3.2 Analisa Data Center Area Pendukung (Supporting Spaces)

Pada kondisi saat ini data center Bank XYZ belum memiliki perencanaan ke depan untuk infrastruktur diantaranya adalah ruangan pendukung data center. Dari hasil pengamatan lapangan ruang pendukung yang terdapat pada data center belum mengakomodasi ruangan data center yang ada. Belum adanya ruangan khusus untuk menyimpan barang atau perlengkapan baru, yang mengakibatkan beberapa penumpukan barang dan perlengkapan pada area data center. Ruang panel masih menjadi satu antara listrik dan data komunikasi. Belum ada staff room yang dekat dengan entrance room berfungsi untuk menampung barang milik staff dan tamu atau pengunjung yang masuk ke data center.

\subsection{Analisis Sistem Kelistrikan (Power Systems)}

Sistem kelistrikan merupakan hal yang sangat vital dalam sebuah pengoperasian data center. Pada data center Bank XYZ telah terdapat ruang utilitas yaitu ruang panel listrik dan UPS yang dalamnya terdapat switch panel listrik yang berfungsi untuk memindahkan arus listrik utama ke 2 buah UPS sebagai sumber daya cadangan sementara apabila PLN padam. Generator listrik yang dimiliki belum sesuai kapasitas yang dibutuhkan data center, sehingga tidak semua sistem akan tetap beroperasi apabila cadangan listrik UPS habis atau bila PLN padam lebih lama dari kemampuan UPS yang ada. 
Posisi generator berada di lantai bawah tanah (basement) terpisah dari ruang data center yang ada di lantai 8. Diperlukan waktu lebih dari 5 menit apabila akan menghidupkan generator tersebut.

\subsection{Analisa Pembangkit Listrik (Generator)}

Pendistribusian listrik pada data center bekerja dengan baik namun switch panel yang terpasang hanya berfungsi mengalihkan listrik utama ke UPS, dan belum bisa memindahkan atau menghidupkan generator apabila UPS habis. Demikian juga apabila listrik utama PLN menyala kembali, tidak dapat melakukan switch back ke sistem listrik utama PLN, hanya bisa dilakukan secara manual.

Data center Bank XYZ belum dilengkapi dengan perangkat Automatic Transfer Switch (ATS), yang berfungsi sebagai switch pengalih daya dari listrik utama PLN ke UPS, dan dari UPS ke Generator apabila pemadaman listrik utama lebih dari 2 jam. ATS tersebut juga bisa mengembalikan posisi panel ke posisi utama apabila listrik utama PLN menyala kembali. Untuk mengatasi terjadinya pemadaman listrik atau sumber daya listrik utama mati, data center Bank XYZ mengandalkan UPS yang dapat menampung daya sekitar 1 jam saja.

\subsection{Analisa Keamanan (Security System)}

Untuk instalasi kabel listrik dan data komunikasi dan beberapa fasilitas pendukung, data center Bank XYZ ini telah menggunakan raised floor yang ukuran 60 $\mathrm{cm}$ x $60 \mathrm{~cm}$ dengan ketinggian $30 \mathrm{~cm}$ dari lantai beton. Perkabelan sudah cukup rapih namun label setiap kabel atau saluran belum ada, sehingga belum bisa diidentifikasi dengan cepat. Hal ini bisa berakibat lamanya respon dan penyelesaiannya apabila terjadi permasalahan pada perkabelan.

Untuk akses masuk ke dalam ruang data center masih belum dilakukan pengamanan secara ketat, dan hanya ada 2 kamera CCTV terpasang yaitu di pintu utama data center dan ruang operator. Sedangkan setiap bagian area data center belum dipasang kamera $C C T V$, sehingga adanya kegiatan yang terjadi di area data center belum bisa dikontrol dengan baik.

Di area rak server terdapat 1 unit alat pemadam kebakaran $(A P A R)$ yang berfungsi sebagai pemadam kebakaran di dalam ruang server. $A P A R$ yang ada belum memenuhi standar khusus untuk data center. Belum ada smoke detector dan alarm yang berfungsi untuk mendeteksi adanya asap akibat hubungan pendek atau sebab lain, hal ini bisa mengakibatkan operator tidak mengetahui bila ada gejala kebakaran.

\subsection{Usulan Rencana Tata Ruang (Space Planning)}

Bedasarkan Standar ANSI/BICSI 002, berikut adalah denah rencana pengembangan ruang data center Bank XYZ untuk kelas F1. Dibawah adalah denah rencana tata ruang data center yang diusulkan :

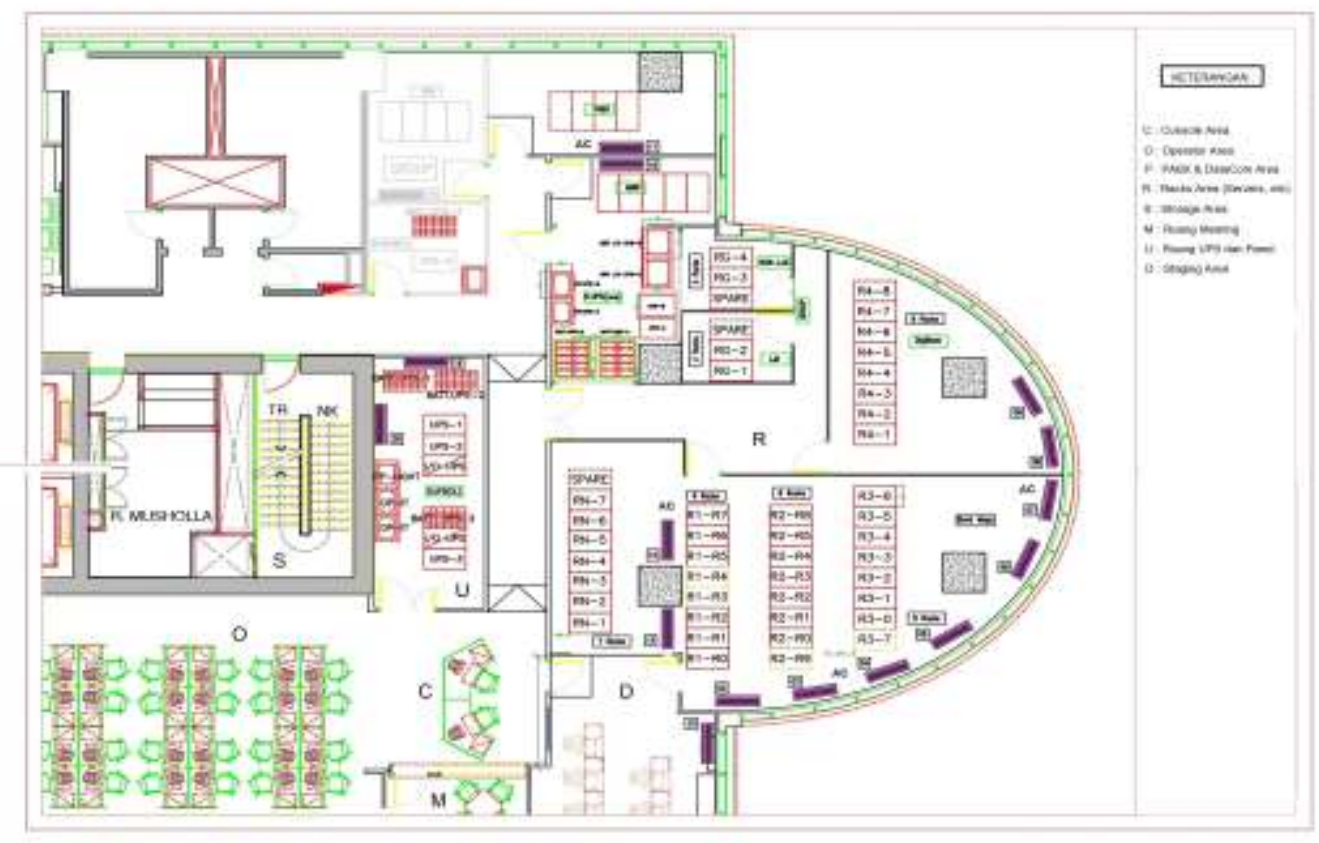

Gambar 6 Denah Rencana Data Center Bank XYZ 


\subsubsection{Rencana Pengembangan Sistem}

Berdasarkan rencana pengembangan sistem yang sudah disetujui oleh manajemen bank, dalam 3 tahun mendatang sistem operasional bank (banking system) akan dikembangkan untuk mengakomodasi pertambahan data sebanyak satu juta nasabah. Sistem kredit (loan system) akan migrasi ke platform/mesin baru, sistem kartu kredit (credit card system) juga dipisahkan dari sistem kredit. Beberapa sistem internal seperti call center dan helpdesk juga akan dipasang, dan beberapa sistem yang terkait dengan regulasi nasional maupun internasional, juga sistem yang terhubung ke lembaga keuangan seperti Bank Indonesia, VISA dan Mastercard, dll. Bank juga akan ekspansi ke seluruh Indonesia dengan menambah kantor cabang sebanyak 250 cabang dan cabang pembantu.

Terkait dengan rencana pengembangan sistem tersebut, maka dibutuhkan penambahan kapasitas beberapa mesin server dan router data komunikasi. Sejalan dengan penambahan mesin-mesin tersebut maka diperlukan juga penambahan kapasitas daya listrik utama PLN dan perangkat backup power cadangan untuk keberlangsungan pasokan daya listrik berupa UPS dan generator yang bisa memenuhi kebutuhan operasional data center (Bank Mega. 2020).

Tabel 1 Daftar Usulan Kebutuhan Data Center baru

\begin{tabular}{|c|c|c|}
\hline NO & Perangkat & Jumlah \\
\hline 1 & $\begin{array}{c}\text { Automatic Transfer Switch } \\
\text { berkapasitas besar }\end{array}$ & 2 \\
\hline 2 & $\begin{array}{c}\text { Generator besar berkapasitas } \\
(300 \text { Kva) }\end{array}$ & 1 \\
\hline 3 & Precision AC & 15 \\
\hline 4 & $\begin{array}{c}\text { UPS besar berkapasitas (100 } \\
\text { Kva) }\end{array}$ & 3 \\
\hline 5 & Smoke Detector & 5 \\
\hline 6 & CCTV Camera & 8 \\
\hline 7 & CCTV Monitor & 1 \\
\hline 8 & Fire Extinguisher & 4 \\
\hline 9 & Secure Access Door & 9 \\
\hline 10 & Server Rack & 4 \\
\hline
\end{tabular}

\subsubsection{Pemisahan Ruang}

Rancangan data center yang baru akan memisahkan area setiap bagian dari fungsional dan fasilitas pendukung data center. Pemasangan dinding pembatas antar ruang dipasang dengan tujuan agar tidak terjadi kesalahan maintenance dan mudah dalam mengidentifikasi setiap bagian masing-masing sistem. Ruang rak server merupakan ruang terluas karena ruang ini berisi semua server seluruh sistem yang beroperasi.
Dinding masing-masing ruang/area terbuat dari dinding partisi untuk bagian bawah, dan kacar tembus pandang untuk bagian atas. Hal ini agar memudahkan data center operator memantau keadaan seluruh perangkat dan mesin yang ada di seluruh ruangan data center. Terutama adalah area console yang harus bisa memantau kondisi mesin server utama.

\subsubsection{Kelistrikan dan Daya Listrik}

Berdasarkan pengembangan sistem dan pengembangan bisnis bank yang telah diputuskan oleh menejemen bank, data center akan ditambah kapasitasnya sehingga memenuhi rencana pengembangan sistem yang diuraikan di 3.6.1 diatas. Dibutuhkan kapasitas daya listrik menjadi 300 kva, secara otomastis dibutuhkan UPS baru dengan kapasitas yang lebih besar yang dapat mengcover listrik apabila terjadi pemadaman listrik PLN. Demikian juga generator harus diganti dengan jenis baru yang mampu memasok kebutuhan listrik apabila listrik PLN padam lebih dari satu jam, atau melebihi kapasitas batere UPS.

Peralatan ATS (automatic transfer switch) dipasang dengan kemampuan yang lebih baik dan berkemampuan untuk melakukan switch over secara otomatis menghidupkan UPS saat listrik PLN padam, dan sebaliknya melakukan pemindahan kembali ke listrik PLN saat listrik PLN kembali hidup. Juga pada saat generator hidup dan akan kembali ke listrik PLN. Hal ini akan memperkecil ketergantungan pada operator.

\subsubsection{Ruang Fungsional}

Ruang fungsional adalah suatu area/ruangan yang diperuntukkan sebagai tempat dimana barang-barang keperluan data center disimpan sementara waktu (loading docks). Juga tempat dimana peralatan yang digunakan oleh staf technical support diletakkan ketika proses instalasi dilakukan atau suatu perbaikan sistem. Keberadaan ruang ini juga sangat membantu apabila diperlukan diskusi atau rapat staf data center bersama staf TI. Ruang ini juga difungsikan untuk tempat istirahat sementara waktu bagi staf data center yang selesai menunaikan tugas, atau yang sedang menunggu giliran tugas.

\subsubsection{Fasilitas Pendukung Sistem}

Dengan bertambahnya mesin server dan perangkat lainnya secara otomatis akan menaikkan temperatur ruangan, sehingga diperlukan sistem pendinginan ruangan data center yang lebih kuat yang dapat menjaga temperatur selalu berada pada 18 derajat Celsius. Toleransi yang diberikan adalah maksimal 21 derajat Celsius. Untuk itu direncanakan akan 
ditambah dengan mesin $A C$ presisi sebanyak 14 mesin portable yang difokuskan pada area rak server utama (ruang R). Sedangkan sistem pendinginan sentral dari gedung tetap disalurkan dari atas lewat plafon ruangan. Untuk ruang operator dan console (ruang $\mathrm{O}$ dan $C$ ) mengandalkan pendinginan dari $A C$ gedung. Demikian juga ruang backup data (ruang S). Untuk ruang $U P S$ (ruang $\mathrm{U}$ ) dan ruang $P A B X$ dan datacom masing-masing dipasang dua unit $A C$ presisi.

Seluruh kabel listrik dan kabel data komunikasi berada dibawah raised floor, dilengkapi dengan label yang mudah diidentifikasi oleh staf. Alat pemadam kebakaran $(A P A R)$ khusus untuk data center dipasang di 4 ruang/area, yaitu area operator, ruang UPS / panel listrik dan Datacom, ruang server utama, dan pintu masuk data center. Sejalan dengan pemasangan $A P A R$, akan dipasang juga Smoke Detector, yang dipasang di beberapa titik pada plafon data center. Smoke detector ini berfungsi mendeteksi adanya asap yang muncul di ruangan/area data center dan terhubung ke alarm. Apabila muncul asap maka alarm akan berbunyi sehingga segera bisa ditangani oleh operator data center.

Monitor CCTV berada di area operator data center, dan selalu dalam keadaan hidup / On. Data rekaman CCTV langsung disimpan dalam server khusus CCTV dengan kapasitas yang mampu menampung data selama 6 bulan, dan secara rutin akan dipindahkan ke backup disk setiap bulan. Hal ini untuk menjamin data rekaman CCTV tidak pernah terhapus selama 24 jam.

\subsubsection{Sistem Keamanan}

Pintu utama data center dan pintu antar ruang atau area satu dengan yang lain akan dipasang pengaman akses (secure access door), dimana setiap staf atau personil yang bisa memasuki adalah staf atau personil yang terdaftar (authorized person). Hal ini bertujuan agar apabila terjadi suatu insiden didalam suatu area data center akan bisa ditelusuri siapa pihak yang memasuki area tersebut.

Sistem monitoring CCTV juga diterapkan dengan memasang 8 kamera di lokasi paling krusial antara lain adalah pintu utama data center, ruang rak server, ruang UPS dan panel listrik, area $P A B X$ dan Datacom, area console dan operator, area barang dan locker staf, ruang penyimpanan data.

Pada pintu utama data center bagian dalam dipasang logbook. Setiap personil baik staf maupun tamu, harus mengisi logbook sebelum dan sesudah memasuki data center. Informasi meliputi jam masuk dan keluar, data identitas pribadi, nama perusahaan, informasi keperluan yang dilakukan, nomor handphone. Selain itu personil dari luar bank harus membawa surat tugas yang sesuai dengan keperluannya.

\subsection{Perbandingan antara Kondisi Saat Ini dengan Kondisi Usulan}

Berdasarkan hasil akhir pada tahap perancangan, dilakukan perbandingan antara kondisi saat ini dengan hasil perancangan data center standar ANSI/BICSI 002 class $F 1$. Berikut adalah tabel perbandingannya.

Tabel 2 Perbandingan Data Center Saat ini dan usulan

\begin{tabular}{|c|c|c|c|c|}
\hline \multirow[t]{2}{*}{ No } & PARAMETER & CLASS F1 & $\begin{array}{l}\text { KONDISI } \\
\text { SAAT INI } \\
\end{array}$ & $\begin{array}{l}\text { KONDISI } \\
\text { USULAN }\end{array}$ \\
\hline & \multicolumn{4}{|c|}{ Power Systems } \\
\hline 1 & Memiliki ruang kelistrikan yang memadai & Dibutuhkan & $\mathrm{V}$ & $\mathrm{V}$ \\
\hline 2 & Memiliki UPS dan baterai berkapasitas cukup & Dibutuhkan & $\mathrm{V}$ & $\mathrm{V}$ \\
\hline 3 & Memiliki ruang panel dan ruang utilitas listrik & Belum dibutuhkan & $\mathrm{V}$ & $\mathrm{V}$ \\
\hline \multirow[t]{2}{*}{4} & Memiliki sistem pendinginan (AC Precison) & Dibutuhkan & $\mathrm{V}$ & $\mathrm{V}$ \\
\hline & \multicolumn{4}{|c|}{ Generator } \\
\hline 1 & Memiliki ruang generator & Dibutuhkan & $\mathrm{X}$ & $\mathrm{V}$ \\
\hline 2 & Generator terpisah dari ruang data center & Dibutuhkan & $\mathrm{X}$ & $\mathrm{V}$ \\
\hline \multirow[t]{2}{*}{3} & $\begin{array}{c}\text { Penyimpanan bahan bakar generator cukup untuk } \\
96 \text { jam berjalan dengan beban yang cukup }\end{array}$ & Belum dibutuhkan & $\mathrm{v}$ & $\mathrm{v}$ \\
\hline & \multicolumn{4}{|c|}{ Security } \\
\hline 1 & Memiliki perangkat $C C T V$ & Belum di butuhkan & $\mathrm{V}$ & $\mathrm{V}$ \\
\hline 2 & Memiliki kontrol akses (Access Control) & Dibutuhkan & $\mathrm{X}$ & $\mathrm{V}$ \\
\hline 3 & Sistem alarm kebakaran (Smoke Detector) & Belum dibutuhkan & $\mathrm{X}$ & $\mathrm{V}$ \\
\hline \multirow[t]{2}{*}{4} & Penggunaan Raised Floor & Dibutuhkan & $\mathrm{V}$ & $\mathrm{V}$ \\
\hline & \multicolumn{4}{|c|}{ Data Center Supporting Spaces } \\
\hline 1 & $\begin{array}{l}\text { Memiliki ruang storage dan loading docks } \\
\text { (fungsiona) }\end{array}$ & Dibutuhkan & $\mathrm{x}$ & $\mathrm{v}$ \\
\hline 2 & Memiliki pintu masuk utama (Entrance Room) & Dibutuhkan & $\mathrm{X}$ & $\mathrm{V}$ \\
\hline 3 & $\begin{array}{c}\text { Memiliki ruang Command Center (Console dan } \\
\text { Operator) }\end{array}$ & Dibutuhkan & v & V \\
\hline
\end{tabular}




\section{KESIMPULAN}

Berdasarkan penelitian yang telah dilakukan, dapat ditarik kesimpulan sebagai berikut:

1. Identifikasi Space Planning kondisi saat ini pada data center Bank XYZ :

a. Data center pada Bank XYZ belum memiliki ruangan fungsional (yang berfungsi sebagai area technical support, ruang meeting, dan penyimpanan barang sementara), ruang generator khusus data center (karena masih tergabung dengan gedung), dan antara ruang/area tidak ada pintu pengaman akses yang sesuai standar ANSI BICSI 002 class F1.

b. Data center pada Bank XYZ belum memiliki perangkat pendukung untuk ruang server yang sesuai dengan standar ANSI/BICSI 002.

c. Untuk memenuhi kebutuhan pengembangan data center kedepan, luas areal/space masih mencukupi hanya diperlukan penataan ulang beberapa peralatan dan rak server sesuai kapasitas yang direncanakan.

2. Usulan desain data center Bank XYZ berdasarkan standar ANSI/BICSI 002 class F1 adalah sebagai berikut :

a. Renovasi ruangan data center yaitu menambahkan sekat antar ruangan/area dan penambahan pengaman akses ke setiap ruangan, hanya untuk staf yang berwenang.

b. Penataan kembali posisi rak-rak server karena penambahan rak-rak baru, penambahan mesin $U P S$ dan $A C$, serta reposisi area console dan penambahan jumlah operator.

c. Penambahan kapasitas UPS dan Generator untuk memenuhi kebutuhan ke depan, dan pemasangan ATS (automatic transfer switch) pada sistem kelistrikan yang lebih canggih dan bisa melakukan switch over maupun switch back arus listrik.

d. Penambahan $A C$ Presisi menyesuaikan dengan pertambahan peralatan/server yang dipasang, untuk menjaga temperatur stabil dan memenuhi standar teknis yang ada.

e. Pengamanan yang lebih baik dengan memasang smoke detector dan CCTV di area spesifik dan bisa dimonitor operator data center, serta penambahan alat pemadam kebakaran $(A P A R)$ khusus data center sesuai kebutuhan.

\section{REFERENSI}

Arregoces, M; Portolani, M. (2004). Data Center Fundamentals. Cisco Press.

Bullock, M. (2009). Data Center Definition and Solutions.

Direction, N. (2017). Network Life Cycle. https://networkdirection.net/articles/network- theory/networklifecycle/

Geng, H. (2014). Data Center Handbook. John Wiley \& Sons.

Systems, C. (2007). Desingnig Cisco Network Service Architectures (ARCH) v1.1.

Tampa, F. L. (2011). ANSI/BICSI 002-2011 Data Center Design and Implementation Best Practices. BICSI.

Wardiana, W. (2012). Perkembangan Teknologi Informasi di Indonesia.

Ye, H.; Song, Z.; Sun, Q. (2014). Design of green data center deployment model based on cloud computing and TIA942 heat dissipation standard.

Yulianti, D.E.; Nanda, H. B. (2008). Best Practice Perancangan Fasilitas Data Center. 